\title{
Evapotranspiration-based Irrigation Scheduling of Head Lettuce and Broccoli
}

\author{
Lee F. Johnson ${ }^{1}$ \\ Division of Science and Environmental Policy, California State University, \\ Monterey Bay, Seaside, CA 93955; and Earth Science Division, NASA Ames \\ Research Center, Moffett Field, CA 94035
}

Michael Cahn

University of California Cooperative Extension, Salinas, CA 93901

Frank Martin

U.S. Department of Agriculture, Agricultural Research Service, Salinas, CA 93905

\section{Forrest Melton}

Division of Science and Environmental Policy, California State University, Monterey Bay, Seaside, CA 93955; and Earth Science Division, NASA Ames Research Center, Moffett Field, CA 94035

\section{Sharon Benzen}

U.S. Department of Agriculture, Agricultural Research Service, Salinas, CA 93905

\section{Barry Farrara \\ University of California Cooperative Extension, Salinas, CA 93901}

\section{Kirk Post}

Division of Science and Environmental Policy, California State University, Monterey Bay, Seaside, CA 93955

Additional index words. irrigation management, fractional cover, crop coefficients, Lactuca sativa, Brassica oleracea

\begin{abstract}
Estimation of crop evapotranspiration supports efficient irrigation water management, which in turn supports water conservation, mitigation of groundwater depletion/ degradation, energy savings, and crop quality maintenance. Past research in California has revealed strong relationships between fraction of the ground covered by photosynthetically active vegetation ( $\mathrm{Fc}$ ), crop coefficients $(\mathrm{Kc})$, and evapotranspiration (ET) of cool-season vegetables and other specialty crops. Replicated irrigation trials for iceberg lettuce and broccoli were performed during 2012 and 2013 at the USDA Agricultural Research Station in Salinas, CA. The main objective was to compare crop yield and quality from ET-based irrigation scheduling with industry standard practice. Sprinkler irrigation was used to germinate and establish the crops, followed by surface drip irrigation during the treatment period. Each experiment compared three irrigation treatment schedules replicated five times in a randomized block design. Two decision-support models were evaluated as follows: 1) an FAO-56-based algorithm embedded in NASA's prototype Satellite Information Management System (SIMS) based on observed Fc, and 2) CropManage (CM), an online database-driven irrigation scheduling tool based on modeled Fc. Both methods used daily reference ETo data from the California Irrigation Management Irrigation System (CIMIS) to translate Kc to crop ET, with a target of $100 \%$ replacement of water use during the drip irrigation phase. A third treatment followed an irrigation schedule representing grower standard practice (SP) at $150 \%$ to $175 \%$ ET replacement during the drip irrigation phase. No significant treatment differences were seen in lettuce head weight or total biomass. Marketable yields of lettuce (near 45.4 Mg.ha ${ }^{-1}$ ) and broccoli (near $17.4 \mathrm{Mg} \cdot \mathrm{ha}^{-1}$ ) were in-line with industry averages during both years and all treatments. During 2012, CM yield was below lettuce SP, and above broccoli SP, while in 2013 no treatment differences were detected for either crop. No significant differences were detected between SIMS and SP yields during any trial.
\end{abstract}

California's central coast is the leading region of cool-season vegetable production in the United States, with Monterey County alone supplying about half of the U.S. lettuce and broccoli production, valued in excess of $\$ 1.5$ billion (Monterey County Crop Report, 2013). These specialty crops are typically well watered to minimize crop stress, meet market quality standards, and attain economically viable yields. Under these standard conditions, high crop transpiration rates are maintained by limited soil drying between wetting events. Vegetable and other specialty crop producers on the Central Coast are under regulatory pressure to reduce nitrate loading to groundwater, which occurs partly as a result of irrigation and resultant leaching of nitrate through the soil profile. In addition, agricultural overdraft has contributed to seawater intrusion into the coastal aquifer. Growers may need to improve both irrigation and nitrogen management of their crops to help address these water quality issues (Cahn et al., 2014).

A need exists for low-cost management strategies including use of irrigation scheduling technologies that incorporate information on meteorological conditions and crop growth stage. The CIMIS, operated by the California Department of Water Resources, operates a network of stations that provide weather data and daily estimates of grass reference ET (ETo) in most agricultural regions of California (Pruitt et al., 1987; Temesgen et al., 2005). Users may access data from the nearest station or from Spatial CIMIS, which provides daily gridded ETo at a 2-km spatial resolution statewide (Hart et al., 2009). ETo inherently accounts for the major meteorological factors affecting crop ET: solar radiation, air temperature, relative humidity, and wind speed.

Though ETo can help estimate crop water requirements, several barriers appear to limit full integration of ETo data into irrigation management practices. Effective use of ETo requires additional calculations to account for factors including crop type, development stage, and site-specific factors, which can be challenging for users to integrate into their daily farm operations. Pretabulated Kc, which relate typical crop water use to ETo as a function of crop stage, can be used to perform an approximate corrections (Allen et al., 2007; Hatfield and Fuchs, 1990). While useful, these simplified guideline values are not available for all crops or crop varieties, nor are they applicable to all management practices and site-specific conditions. Lacking accessible decision support tools with demonstrated performance, producers may apply more water than needed to attain viable economic yields. Development of convenient, user-friendly decision support tools that provide customized field information may therefore serve to increase adoption of ET-based practices for on-farm irrigation scheduling.

Two recent decision-support models, both incorporating CIMIS ETo, were tested in replicated large-plot trials. Both models use crop fractional cover $(\mathrm{Fc})$, or the proportion of the field covered by photosynthetically active vegetation, to derive crop coefficients that are customized to actual growing conditions. Fc is a prime determinant of surface albedo and absorption of solar radiation by the crop canopy, and exerts a direct influence on energy exchange at the land surface that drives the evapotranspiration process (Allen 
et al., 1998). As such, estimates of Fc can provide a basis for Kc and crop ET (ETc) monitored in vegetables (Bryla et al., 2010; Gallardo et al., 1996; Goorahoo et al., 2014; Grattan et al., 1998) and other crops (Allen et al., 2007; Allen and Pereira, 2009).

The first model tested was the CM irrigation scheduling tool previously developed by U.C. Cooperative Extension (Cahn et al., 2013, 2014). CM combines crop coefficients and evaporation coefficients with CIMIS ETo to develop irrigation schedules meeting daily crop water requirements of lettuce, broccoli, and other cool-season vegetables. As well, $\mathrm{CM}$ integrates a nitrogen management component as described by Bottoms et al. (2012) and Cahn et al. (2014). The model assumes crops are well watered (experience no water stress), transpiration is a direct function of Fc, and ETc can be explained strictly in terms of either plant transpiration or soil evaporation on a given day. $\mathrm{Fc}$ is estimated based on empirical data collected from commercial vegetable fields. While CM was previously tested and demonstrated on nonreplicated plots in commercial fields, this project presented an opportunity to further evaluate model performance in a well-controlled setting with replicated treatments.

The second model tested was NASA's prototype SIMS, developed in collaboration with California State University (Melton et al., 2012). SIMS combines public Earthobservation satellite imagery with FAO-56based calculations (Allen et al., 1998; Allen and Pereira, 2009) and CIMIS ETo (Johnson et al., 2010, 2011; Melton et al., 2012). Satellite data are used to estimate Fc (Johnson and Trout, 2012), which is then converted to basal crop coefficients (Kcb) and basal ETc. The basal coefficients describe plant transpiration plus diffuse soil evaporation. The experiments described here offered an opportunity to examine the efficacy of the SIMS Fc-Kcb conversion with respect to yield response.

Both models are currently available to the user community. $\mathrm{CM}$ is a comprehensive model that makes specific recommendations on both irrigation and fertilizer application on a per-field basis. The CM model currently operates only on well-watered vegetables and berries common to Salinas Valley, while expansion to other crops and regions is under development. The SIMS model provides ET

\footnotetext{
Received for publication 24 Apr. 2015. Accepted for publication 26 Apr. 2016.

The project was sponsored by the California Dept. Food \& Agriculture no. SCB1 1016 with additional support from NASA's Applied Sciences Program. Commercial cooperators Fresh Express and Tanimura \& Antle harvested the crops and evaluated, or provided guidance on collection of, associated crop quality data. We thank Sakata, Enza, and Seminis for donating seeds, and Wilbur-Ellis for fertilizer. David Lara and Gerry Ochoa (USDA-ARS) contributed to agricultural operations.

${ }^{1}$ Corresponding author. E-mail: lee.f.johnson@nasa. gov.
}

estimates to facilitate crop water use for current or retrospective evaluation. Unlike CM, SIMS makes no specific recommendation on irrigation amount, but the user may download and sum daily data over a time period of interest. Information on irrigation schedule, as available to the model through these experiments, is needed to fully evaluate fields with significant bare-soil evaporation component or crop water stress. Implemented as a satellite-based system, SIMS output is spatially explicit and currently covers most irrigated land in California. Ongoing work involves development of web data services and an application program interface to integrate satellite-derived output from SIMS with CM. Such data sharing is intended to leverage the strengths of both tools for estimation of ET and irrigation requirements across a wide range of crop types, growing conditions, and agronomic practices.

The project goal was to evaluate ETbased irrigation scheduling of cool-season vegetables using CM and SIMS models and CIMIS ETo values in replicated trials. Relationships between applied water and crop yields were evaluated. Crops were grown using standard regional production, cultivation, and harvest practices.

\section{Materials and Methods}

Replicated field trials in iceberg lettuce (Lactuca sativa) and broccoli (Brassica oleracea) were performed during 2012 and 2013 at the USDA Agricultural Field Station near Salinas, CA $\left(36.6^{\circ} \mathrm{N},-121.5^{\circ} \mathrm{W}\right)($ Table 1$)$. Separate 0.57 ha fields located on a Chualar sandy loam soil were used for the lettuce and broccoli trials, with the crops direct seeded in two seedlines per bed. The seedlines were separated by $30 \mathrm{~cm}$, with $1 \mathrm{~m}$ bed spacing. All trials were germinated and established using sprinkler irrigation. In Salinas Valley, typically $100-120 \mathrm{~mm}$ of sprinkler irrigation is required to saturate the soil and promote uniform stands. Lettuce was thinned to $20-30 \mathrm{~cm}$ plant spacing along the row $\approx 3$ weeks after seeding. Broccoli crops were seeded at $13 \mathrm{~cm}$ spacing and were not thinned after establishment. Experimental irrigation treatments were imposed by surface drip irrigation after crop establishment. Single drip lines were placed equidistant between seedlines on the bed surface. Drip emitters were spaced $30 \mathrm{~cm}$ apart and had a discharge rate of $1 \mathrm{~L}$ per hour per emitter at $55 \mathrm{kPa}$. Treatments were grower standard practice (T1-SP), crop ET replacement based on SIMS (T2-SIMS), and crop ET replacement based on CM (T3-CM) recommendation. Irrigation treatments were randomly assigned to plots following a complete block design with five replicates per treatment. For all trials except Broccoli-2013, replicated plot size was eight beds by $41 \mathrm{~m}$. Plots for Broccoli-2013 were reduced to six beds by either 37 or $49 \mathrm{~m}$ to negate an area of birdrelated damage to emergent plants. All crops were grown in compliance with local commercial agronomic and cultivation practices.

An irrigation manifold with flowmeters was used to independently control water
Table 1. Irrigation trial summary calendar.

\begin{tabular}{lrcr}
\hline Expt. & Seeded & Harvested & $\begin{array}{r}\text { Total } \\
\text { days }\end{array}$ \\
\hline Lettuce-2012 & 1 May & 11 July & 71 \\
Lettuce-2013 & 30 Apr. & 8 July & 69 \\
Broccoli-2012 & 25 July & 19-29 Oct. & 93 \\
Broccoli-2013 & 23 July & 23 Oct.-4 Nov. & 104 \\
\hline
\end{tabular}

${ }^{\mathrm{z}}$ Series of three cuttings.

applications to each experimental treatment. The irrigation interval was generally every 3-4 d. For each drip irrigation event, applied water for T1-SP was specified as a multiple of the applied water on T3-CM. The multiple was 1.5 for lettuce and 1.75 for broccoli. These values were specified a priori to generate T1-SP seasonal irrigation totals near the midpoint of typical applied water totals for each crop as reported by UC-ANR $(2010,2011)$ as follows. For lettuce, typical application is $300-450 \mathrm{~mm}$ by drip (including sprinkler establishment) in the Central Coast. For broccoli, the reported total is $450-760 \mathrm{~mm}$ by sprinkler, as use of drip for this crop is uncommon on the Central Coast during summer due to perceived difficulty of achieving quality standards under high evaporative demand conditions. Subsequent monitoring of 10 commercial broccoli fields under sprinkler and drip irrigation during 2012-13 revealed average applied water of $600 \mathrm{~mm}$, which was near the midpoint of the UC-ANR range (Cahn, unpublished data). Drip totals for broccoli exceeded $760 \mathrm{~mm}$ in two fields (Cahn et al., 2014).

Upon crop establishment, Fc was measured every 3 to $4 \mathrm{~d}$ through maximum foliar expansion in T2-SIMS to support ET calculations, with periodic measurements taken in T1-SP and T3-CM for comparison purposes. In early growing stages, when plants were discrete $(<30 \mathrm{~cm}$ diameter for post-thinned lettuce, $<13 \mathrm{~cm}$ for broccoli), Fc was estimated on the basis of plant size measurements taken by meter stick. Thereafter, as neighboring plants began to merge, Fc estimates were based on nadir-view photographs taken with a multispectral Agricultural Digital Camera (TetraCam Inc., Chatsworth, $\mathrm{CA}$ ) positioned level to the ground at $\approx 3 \mathrm{~m}$ elevation. Each photograph was processed with PixelWrench ${ }^{\circledR}$ canopy segmentation software to separate vegetation pixels from soil substrate by an iterative supervised classification process based on the spectral response in the red and near infrared wavelengths. Soil nitrogen status was monitored with soil nitrate Quick Test strips, and standard fertility practices were followed (UC-ANR 2010, 2011).

CropManage. For a given day during the growth cycle, $\mathrm{CM}$ calculated $\mathrm{Fc}$ as:

$$
\begin{aligned}
\mathrm{Fc}= & \mathrm{Cmax} /(1+\exp (\mathrm{A}+\mathrm{B} \\
& \times \mathrm{DAP} / \text { Maxday })) / 100
\end{aligned}
$$

where Cmax is expected maximum canopy cover in percentage terms, A and B are fitted parameters that are specific to crop type and planting configuration, DAP is the number of 
days after planting, and Maxday is total days between planting and harvest. The equation follows Eq. [4] of Gallardo et al. (1996), but uses day count rather than normalized cumulative ETo. Nominal coefficient values for various crops and planting configurations were derived by prior measurements made periodically with a ground-based Agricultural Digital Camera (TetraCam Inc.) during the crop cycle in several commercial fields (Cahn et al., 2014). Coefficient values for $\{\mathrm{Cmax}, \mathrm{A}$, $\mathrm{B}$, Maxday $\}$ were $\{83,6.78,-11.61,71\}$ for the lettuce trial, and $\{98,5.57,-12.21,86\}$ for broccoli. Weather variations due to seasonal or interannual variability can be accounted for by adjusting Maxday to expand or contract the growth curve to better match observed crop development. Most commercial vegetable growers know the number of days between planting and harvest of the varieties that they produce for different times of the year.

A daily transpiration coefficient $(\mathrm{T})$, representing the transpiration component of ETc, was derived from canopy cover, as:

$$
\mathrm{T}=-0.39 \mathrm{Fc}^{2}+1.5 \mathrm{Fc}
$$

Eq. [2] was derived from Eq. [5] of Gallardo et al. (1996). The Gallardo equation relates groundcover to daily radiation interception, which is strongly related to Kc. The original Gallardo coefficients were empirically modified through subsequent commercial field trials (Cahn, unpublished data) to more reliably meet industry standard yields. The approach of estimating Kc directly from canopy cover is broadly consistent with findings of Grattan et al. (1998).

A daily soil evaporation coefficient $(\mathrm{Ke})$ was derived to represent the evaporation component of ETc. For sprinkler irrigation and rainfall, which wet the entire field surface, values for Ke were set to 1.0 on the day of event, 0.4 the following day, 0.05 two days after event, and zero thereafter. For drip irrigation, which wets only $\approx 30 \%$ of the field surface, values for Ke were set to 0.3 on day of event, 0.1 the following day, 0.05 two days after event, and zero thereafter. These Ke values were empirically determined by comparing ETo with soil moisture drawdown estimated by gravimetric measurement of water content in soil cores taken from the top $15 \mathrm{~cm}$ and at $30-\mathrm{cm}$ intervals to a depth of $105 \mathrm{~cm}$ following bare-soil wetting events (after Gallardo et al., 1996).

For cool-season vegetables established by sprinkler and then converted to drip, ETc is dominated by soil evaporation initially, when cover and transpiration are low or zero, and thereafter by transpiration. Thus, as a simplification, $\mathrm{CM}$ sets daily $\mathrm{Kc}$ to the greater of $\mathrm{T}$ and $\mathrm{Ke}$ :

$$
\mathrm{Kc}=\max [\mathrm{T}, \mathrm{Ke}]
$$

Satellite Information Management System. Ground measurements were used for Fc monitoring as plot sizes were smaller than typical fields and hence did not support satellite observation. For both crops, Fc was converted to Kcb by a generic equation for annual crops (Melton et al., 2012):

$$
\mathrm{Kcb}=-0.4766 \mathrm{Fc}^{2}+1.4048 \mathrm{Fc}+0.15
$$

This equation was derived by independently applying the density coefficient approach of Allen et al. (2007) and Allen and Pereira (2009) through an Fc range of 0.1-0.9 for small (low stature) vegetables and other major crop classes listed in FAO-56 (Allen et al., 1998). Crop heights were derived as a function of $\mathrm{Fc}$ applied to maximum class height $\left(\mathrm{h}_{\max }\right)$, which was calculated by averaging maximum heights for all individual crops per FAO-56 class. A linear relationship between $\mathrm{Fc}$ and crop height, with $\mathrm{h}_{\max }$ occurring at $70 \%$ cover, was assumed.

$\mathrm{Ke}$ was calculated by the standard FAO56 method on day of wetting to account for stage-1 evaporation, and set to zero on other days. An observed value of 0.3 was used for fraction of surface wetted by drip irrigation $\left(f_{w}\right)$, and the surface fraction that was both exposed and wetted $\left(f_{\text {ew }}\right)$ was calculated as:

$$
\mathrm{f}_{\mathrm{ew}}=\min \left[\left(1-\mathrm{Fc},(1-0.67 \mathrm{Fc}) \mathrm{f}_{\mathrm{w}}\right)\right]
$$

The final SIMS crop coefficient was derived after the FAO-56 dual crop coefficient formulation (Allen et al., 1998) as:

$$
\mathrm{Kc}=\mathrm{Kcb}+\mathrm{Ke}
$$

Irrigation depth. Both models monitored daily crop ET as:

$$
\mathrm{ETc}=\mathrm{ETo} \times \mathrm{Kc}
$$

For a given irrigation event, daily ETc was summed to derive cumulative ETc ( $\left.\sum E T c\right)$ since last irrigation. Final irrigation water depths $(\mathrm{mm})$ for the CM and SIMS treatments were derived as:

$$
\mathrm{I}=\Sigma \mathrm{ETc} / \mathrm{DU}-\mathrm{P}
$$

where DU was estimated irrigation system distribution uniformity, and was used to help ensure that adequate water was supplied to parts of the field with the lowest application amount. For this study, a DU value of 0.9 was used for lettuce, and 0.85 for broccoli. Both values are within the typical range for drip irrigation systems as deployed in the Salinas region. The lower DU value was used for broccoli to account for additional drip tape wear expected with the longer crop cycle, relative to lettuce. $\mathrm{P}$ is precipitation, which was negligible during all trials.

Lettuce-2012. Iceberg lettuce (Gabilan var.) was seeded on 1 May. ETo data were measured by the nearest CIMIS station (no. 89 ), which was situated $\approx 2.4 \mathrm{~km}$ southeast of the field trial. The crop was thinned on DAP 24 and surface drip irrigation was initiated on DAP 28. Head weights, total and harvestable plant populations, biomass yields, and carton yields were measured on DAP 70. Forty heads were randomly selected and harvested from a $30 \mathrm{~m}$ section of the center 4 beds within each plot. Heads were immediately weighed, trimmed to market specifications by removing exterior leaves, then reweighed. Biomass yield was estimated as the product of untrimmed head weight and total plant population. Marketable carton yield was estimated as the product of trimmed head weight and marketable plant population. On DAP 71, a commercial cooperator harvested to determine cored-for-region (CFR) yield, which is intended for the fresh-cut industry as distinct from a shredded or chopped product. The CFR harvest process involved removing the central core and part of the outer portion of each head. Heads with obvious defects (immature, disease/bird damage, growth defects) were not picked. The center six beds of each plot were harvested to fill one bin with a volume of $1.2 \mathrm{~m}^{3}$. Each bin was weighed and the corresponding harvested area was recorded.

During both years, subsamples of harvested CFR product from T1-SP and T2-SIMS were cooled to $1^{\circ} \mathrm{C}$, then processed and packaged at a commercial facility. The product was then stored at $4{ }^{\circ} \mathrm{C}$ for $17 \mathrm{~d}$, and professional evaluations were conducted for sensory attributes (flavor, texture, aroma, visual appearance) and shelf life performance based on physiological, processing, and postharvest storage defects including "tip burn," large pieces ("chunks"), decay, browning, vascular discoloration, and translucency. Since the water regime for T3-CM was similar to T2-SIMS, the $\mathrm{CM}$ treatment was excluded from postharvest evaluation.

Lettuce-2013. Iceberg lettuce (Telluride var.) was seeded on 30 Apr. The field was the same as was used in 2012, though the treatments were rerandomized in the blocks. The crop was thinned on DAP 22 and converted to surface drip on DAP 29. Reference ETo was reported by CIMIS station no. 214, which replaced station no. 89 on 17 May 2013 and was situated $1 \mathrm{~km}$ northeast of the field trial. Head weights, total biomass, and carton yields were estimated on DAP 64, by methods described for 2012. The field was harvested for CFR product by a commercial cooperator on DAP 69, per 2012 methods.

Broccoli-2012. Broccoli (Patron var.) was seeded on 25 July and surface drip was initiated on DAP 30. Daily reference ETo was monitored by nearby CIMIS station no. 89 until DAP 60 when it was retired from service, and Spatial CIMIS was used thereafter. Harvest involved three manual cuttings performed by a commercial cooperator following standard practices. The first cutting (DAP 86) included only plants that matured to crown-sized heads $(10-18 \mathrm{~cm}$ diameter, $10-13 \mathrm{~cm}$ length), the second cutting (DAP 90) was a mix of crowns and bunch-sized (6-10 cm diameter, 18-20 cm length) heads, the third cutting (DAP 93) was only bunchsize heads. The harvest area comprised the center $30 \mathrm{~m}$ of the middle of each plot. Average crown and bunch-sized head weights of plots were determined from a random sample of 50 heads. Head quality was evaluated on-site for common defects including hollow-stem, excessive branching, over-maturity, pest damage, cat eye, and brown bead.

Broccoli-2013. Broccoli (Patron var.) was seeded on 23 July. The field was the same as 
was used in 2012, though the treatments were rerandomized in the blocks. The field was converted to surface drip on DAP 31. Reference ETo was monitored by CIMIS station no. 214. Harvest involved three cuttings performed by a commercial cooperator following standard practices of 2012. The first cutting (DAP 92) was for crowns only, the second and third cuttings (DAP 97, 104) was a mix of crown and bunch. The harvest area was the center $20 \mathrm{~m}$ of the middle four beds of each plot. Average head weight, quality, and defects were evaluated during each cutting as described for 2012 .

Statistical analysis. The general linear means procedures of the Statistical Analysis System (SAS) were used to statistically evaluate differences in yield and quality among irrigation treatments at a significance level of $P<0.05$. Quality data for CFR lettuce were $\log$ transformed for statistical analysis. Multiple means comparisons were performed when main effects were found to be statistically significant using a protected Fisher's test, two tailed $(P<0.05)$.

\section{Results and Discussion}

Lettuce. During 2012, drip irrigation totals were $280 \mathrm{~mm}$ for T1-SP, $168 \mathrm{~mm}$ for T2SIMS, and $183 \mathrm{~mm}$ for T3-CM. In addition, $112 \mathrm{~mm}$ of sprinkler irrigation was applied per treatment during germination and establishment (Table 2). No significant differences were found among treatments with respect to head weight, biomass yield, or marketable yield for carton lettuce (Table 3). No statistical difference was found between CFR yields of T1-SP (47.7 Mg.ha- ${ }^{-1}$ and T2SIMS (45.7 Mg.ha ${ }^{-1}$ ), while lower yield in T3-CM (42.4 Mg.ha ${ }^{-1}$ ) was statistically significant. Field surveys indicated that T3-CM suffered a higher incidence of bird damage. Considering this factor, and that the T2-SIMS yield was achieved with less water, it is probable that the lower T3-CM yield was

Table 2. Drip irrigation events and applied water totals $(\mathrm{mm})$ for lettuce trials.

\begin{tabular}{|c|c|c|c|c|}
\hline Trial & DAP & T1-SP & T2-SIMS & T3-CM \\
\hline \multirow[t]{10}{*}{ Lettuce-2012 } & $28^{z}$ & 17 & 17 & 18 \\
\hline & 34 & 11 & 10 & 8 \\
\hline & 38 & 11 & 7 & 7 \\
\hline & 42 & 24 & 14 & 15 \\
\hline & 47 & 33 & 19 & 22 \\
\hline & 50 & 20 & 13 & 13 \\
\hline & 55 & 56 & 24 & $36^{\mathrm{y}}$ \\
\hline & 59 & 43 & 24 & 25 \\
\hline & 63 & 38 & 22 & 23 \\
\hline & 66 & 25 & 18 & 17 \\
\hline Total drip & & 280 & 168 & 183 \\
\hline Grand total incl. sprinkler ${ }^{x}$ & & 392 & 280 & 295 \\
\hline \multirow[t]{12}{*}{ Lettuce-2013 } & $29^{z}$ & 18 & 20 & 20 \\
\hline & 34 & 12 & 10 & 8 \\
\hline & 38 & 13 & 9 & 9 \\
\hline & 42 & 16 & 12 & 11 \\
\hline & 45 & 18 & 13 & 12 \\
\hline & 48 & 23 & 16 & 15 \\
\hline & 51 & 23 & 16 & 15 \\
\hline & 55 & 31 & 23 & 26 \\
\hline & 59 & 31 & 20 & 18 \\
\hline & 62 & 33 & 21 & 20 \\
\hline & 63 & 18 & 13 & 10 \\
\hline & 64 & 18 & 8 & 26 \\
\hline Total drip & & 254 & 180 & 170 \\
\hline Grand total incl. sprinkler & & 358 & 284 & 274 \\
\hline
\end{tabular}

${ }^{\mathrm{z} F i r s t}$ drip event about equalized across treatments.

y Includes extra $13 \mathrm{~mm}$ due to operational error.

xPlus 3-mm precipitation. the result of factors other than water shortage. All CFR yields exceeded the local industry average of $41.5 \mathrm{Mg} \cdot \mathrm{ha}^{-1}$ (Fresh Express, personal communication). Shelf life and quality of the CFR product, assessed by a commercial collaborator, were not statistically different among treatments (data not shown).

In 2013, drip irrigation totals were $254 \mathrm{~mm}$ for T1-SP, $180 \mathrm{~mm}$ for T2-SIMS, and $170 \mathrm{~mm}$ for T3-CM (Table 2). An additional $104 \mathrm{~mm}$ was applied by sprinkler. No significant differences were observed among treatments for head weight, biomass yield, or marketable yield for carton lettuce (Table 3). As well, no significant differences in CFR yields were found. As in 2012, all CFR yields exceeded the local-industry average, and no significant differences were found regarding quality and shelf life of CFR product (data not shown). In both years, the T2-SIMS and T3-CM irrigation totals (sprinkler plus drip) agreed well with Bryla et al. (2010), who reported $275 \mathrm{~mm}$ consumptive use for head lettuce on a weighing lysimeter in San Joaquin Valley during autumn.

Broccoli. Drip irrigation totals in 2012 were $394 \mathrm{~mm}$ for T1-SP, $249 \mathrm{~mm}$ for T2SIMS, and $236 \mathrm{~mm}$ for T3-CM, plus $124 \mathrm{~mm}$ per treatment by sprinkler. Drip irrigation totals in 2013 were $470 \mathrm{~mm}$ for T1-SP, $290 \mathrm{~mm}$ for T2-SIMS, and $272 \mathrm{~mm}$ for T3CM (Table 4), with an additional $119 \mathrm{~mm}$ by sprinkler. For both years, all marketable yields were near $17.9 \mathrm{Mg} \cdot \mathrm{ha}^{-1}$, which is the statewide industry average (UC-ANR, 2010). T3-CM had significantly higher total marketable yield than T1-SP in 2012, while yields were not significantly different in 2013 (Table 5). In 2012, no statistically significant difference was observed among defect rates for bunch, which ranged from $5.2 \%$ to $6.6 \%$. In 2013, branchiness was significantly higher for T1-SP and T3-CM compared with T2SIMS, and was the main defect observed. T1SP had a significantly higher defect rate for crown ( $8.8 \%$ vs. $4.2 \%$ for T2-SIMS and $5.5 \%$ for T3-CM; data not shown). The T2-SIMS and T3-CM drip totals for both years were above that of Bryla et al. (2010), who reported consumption of $220 \mathrm{~mm}$ (198 by subsurface drip irrigation, $22 \mathrm{~mm}$ rain) in San Joaquin Valley following crop

Table 3. Yields from lettuce trials.

\begin{tabular}{|c|c|c|c|c|c|c|c|}
\hline \multirow[b]{3}{*}{ Treatment } & \multicolumn{2}{|c|}{ Head wt } & \multicolumn{2}{|c|}{ Plant population } & \multirow[b]{2}{*}{$\underline{\text { Biomass yield }}$} & \multicolumn{2}{|c|}{ Marketable yield } \\
\hline & Untrimmed & Trimmed & Total & Marketable & & Carton pack & $\mathrm{CFR}^{\mathrm{z}}$ commercial \\
\hline & \multicolumn{2}{|c|}{$\mathrm{kg} / \mathrm{head}$} & \multicolumn{2}{|c|}{ Plants/ha } & \multicolumn{3}{|c|}{$\mathrm{Mg} \cdot \mathrm{ha}^{-1}$} \\
\hline \multicolumn{8}{|l|}{$\overline{2012}$} \\
\hline T1-SP & 1.63 & 1.16 & 64,729 & 63,936 & 105.5 & 74.4 & $47.7 \mathrm{a}$ \\
\hline T2-SIMS & 1.57 & 1.17 & 66,555 & 65,844 & 104.2 & 77.1 & $45.7 \mathrm{a}$ \\
\hline T3-CM & 1.56 & 1.12 & 64,050 & 63,662 & 99.9 & 71.7 & $42.4 \mathrm{~b}$ \\
\hline $\operatorname{LSD}_{0.05^{\mathrm{y}}}$ & NS & NS & NS & NS & NS & NS & 2.9 \\
\hline \multicolumn{8}{|l|}{2013} \\
\hline T1-SP & 1.24 & 0.72 & 66,847 & 66,056 & 82.9 & 47.6 & 45.9 \\
\hline T2-SIMS & 1.22 & 0.71 & 68,026 & 67,299 & 83.0 & 47.8 & 46.4 \\
\hline T3-CM & 1.25 & 0.73 & 67,766 & 67,008 & 84.7 & 48.9 & 44.4 \\
\hline $\mathrm{LSD}_{0.05}$ & NS & NS & NS & NS & NS & NS & NS \\
\hline
\end{tabular}

${ }^{\mathrm{z} C o m m e r c i a l l y ~ h a r v e s t e d, ~ c o r e d ~ f o r ~ r e g i o n a l ~ s p e c i f i c a t i o n s . ~}$

${ }^{y}$ Critical value for Fisher's least significant difference pairwise test at the $P<0.05$ level. Significant differences are shown by a,b. Ns means are not statistically different at the $P<0.05$ level. 
establishment. The T2-SIMS and T3-CM drip totals agreed somewhat better with Lopez-Urrea et al. (2009), who found consumptive use of $249 \mathrm{~mm}$ (exclusive of soil evaporation) for sprinkler-irrigated broccoli in central Spain.

Table 4. Drip irrigation events and applied water totals $(\mathrm{mm})$ for broccoli trials.

\begin{tabular}{|c|c|c|c|c|}
\hline Trial & DAP & T1-SP & T2-SIMS & T3-CM \\
\hline \multirow[t]{20}{*}{ Broccoli-2012 } & $30^{\mathrm{z}}$ & 14 & 13 & 13 \\
\hline & 34 & 6 & 8 & 4 \\
\hline & 37 & 8 & 12 & 6 \\
\hline & 41 & 19 & 13 & 10 \\
\hline & 44 & 22 & 14 & 14 \\
\hline & 48 & 28 & 20 & 15 \\
\hline & 51 & 19 & 12 & 11 \\
\hline & 55 & 25 & 20 & 21 \\
\hline & 58 & 23 & 13 & 14 \\
\hline & 61 & 24 & 12 & 12 \\
\hline & 65 & 31 & 16 & 16 \\
\hline & 68 & 25 & 14 & 13 \\
\hline & 71 & 25 & 18 & 19 \\
\hline & 74 & 19 & 10 & 11 \\
\hline & 77 & 21 & 11 & 11 \\
\hline & 79 & 9 & 5 & 5 \\
\hline & 83 & 23 & 13 & 13 \\
\hline & 86 & 24 & 13 & 14 \\
\hline & 90 & 13 & 4 & 4 \\
\hline & 93 & 14 & 7 & 10 \\
\hline Total drip & & 394 & 249 & 236 \\
\hline Grand total incl. sprinkler ${ }^{y}$ & & 518 & 373 & 360 \\
\hline \multirow[t]{21}{*}{ Broccoli-2013 } & $31^{z}$ & 16 & 16 & 16 \\
\hline & 36 & 15 & 14 & 9 \\
\hline & 39 & 10 & 8 & 8 \\
\hline & 43 & 21 & 16 & 12 \\
\hline & 45 & 23 & 15 & 14 \\
\hline & 49 & 24 & 15 & 13 \\
\hline & 52 & 29 & 16 & 15 \\
\hline & 56 & 21 & 13 & 12 \\
\hline & 59 & 24 & 14 & 14 \\
\hline & 62 & 33 & 17 & 17 \\
\hline & 66 & 33 & 20 & 19 \\
\hline & 69 & 25 & 15 & 14 \\
\hline & 72 & 24 & 13 & 14 \\
\hline & 75 & 36 & 21 & 21 \\
\hline & 78 & 30 & 15 & 14 \\
\hline & 80 & 27 & 14 & 15 \\
\hline & 84 & 24 & 14 & 14 \\
\hline & 87 & 20 & 12 & 11 \\
\hline & 91 & 16 & 9 & 9 \\
\hline & 94 & 4 & 3 & 2 \\
\hline & 100 & 16 & 8 & 8 \\
\hline Total drip & & 470 & 290 & 272 \\
\hline Grand total incl. sprinkler ${ }^{x}$ & & 589 & 409 & 391 \\
\hline
\end{tabular}

${ }^{\mathrm{x}}$ First drip event about equalized across treatments.

yPlus $8 \mathrm{~mm}$ precipitation.

${ }^{x}$ Plus $7-\mathrm{mm}$ precipitation.
Model comparison. Satisfactory correspondence was seen between measured and $\mathrm{CM}$ modeled $\mathrm{Fc}$ for broccoli in both years and lettuce in 2013, suggesting that development rate of these crops is reasonably predictable under local growing conditions (Fig. 1).
For Lettuce-2012, however, measured cover lagged predicted by as much as $31 \%$ during the rapid expansion phase, though both ultimately reached about the same maximum value of $\approx 80 \%$. This discrepancy was likely due to use of the Gabilan variety for this trial. $\mathrm{Fc}$ under the $\mathrm{CM}$ model is calibrated to Telluride and other varieties typically used in the local area. The Gabilan variety is better suited to warmer and more southerly locations, resulting in slower expansion under the prevailing weather conditions at the field site. It is recommended that modified coefficients be developed to reflect the growth pattern of Gabilan if its use is expanded in the Salinas region. A complementary option would be to add a degree-day component to the Fc computation to better account for effects of air temperature regime on canopy expansion.

Applied water recommendations from the two models were in good agreement for all trials (Tables 2 and 4). Drip irrigation totals for T2-SIMS exceeded T3-CM by $5 \%$ to $7 \%$ for Lettuce-2013, Broccoli-2012, and Broccoli2013. SIMS is designed to support large-area satellite-based ET mapping under conditions where specific crop type, at least for annuals, is unknown. As such, it uses a Fc-Kcb conversion (Eq. 4) designed for use on all annual crops, and this best-fit equation somewhat overestimates Kc of small vegetables (Melton et al., 2012). During Lettuce-2012 on the other hand, the T3-CM drip total exceeded T2-SIMS by $9 \%$. This was due primarily to CM over-estimation of Fc due to use of a nonstandard cultivar as noted above, combined with an experimental error of $+13 \mathrm{~mm}$ of water applied to T3-CM on DAP 55.

Comparison with standard practice. For lettuce over both years, T1-SP received an additional $74-112 \mathrm{~mm}$ water, a relative increase of $26 \%$ to $40 \%$ over the crop cycle, as compared with T2-SIMS and T3-CM. For broccoli, additional water on T1-SP ranged from 145 to $198 \mathrm{~mm}$, an increase of $39 \%$ to $51 \%$ over T2-SIMS and T3-CM. Despite this additional irrigation, no statistical yield or quality difference was observed between T2SIMS and T1-SP in any trial. For T3-CM, CFR yields were significantly lower than T1-SP for Lettuce-2012, possibly due to higher rates of bird-related damage rather than water reduction, whereas no difference was seen in biomass or carton yield. T3-CM yield was significantly

Table 5. Yields from broccoli trials. Each trial involved three separate cuttings yielding a mix of commercial products: crown and bunch. Shown are sums from all cuttings.

\begin{tabular}{|c|c|c|c|c|c|c|}
\hline & Crown yield & Marketable crown yield & Bunch yield & Marketable bunch yield & Total yield & Total marketable yield \\
\hline Treatment & \multicolumn{6}{|c|}{ Mg.ha' ${ }^{-1}$} \\
\hline T1-SP & 8.36 & 7.62 & $9.97 \mathrm{a}$ & $9.28 \mathrm{a}$ & 18.33 & $16.90 \mathrm{a}$ \\
\hline $\operatorname{LSD}_{005}{ }^{\mathrm{z}}$ & NS & NS & 1.14 & 0.53 & NS & 1.19 \\
\hline \multicolumn{7}{|l|}{2013} \\
\hline T1-SP & 9.16 & 8.63 & 9.23 & 8.65 & 18.40 & 17.28 \\
\hline $\operatorname{LSD}_{0.05}$ & NS & NS & NS & NS & NS & NS \\
\hline
\end{tabular}

${ }^{2}$ Critical value for Fisher's least significant difference pairwise test at the $P<0.05$ level. Significant differences are shown by a,b. Ns means are not statistically different at the $P<0.05$ level. 

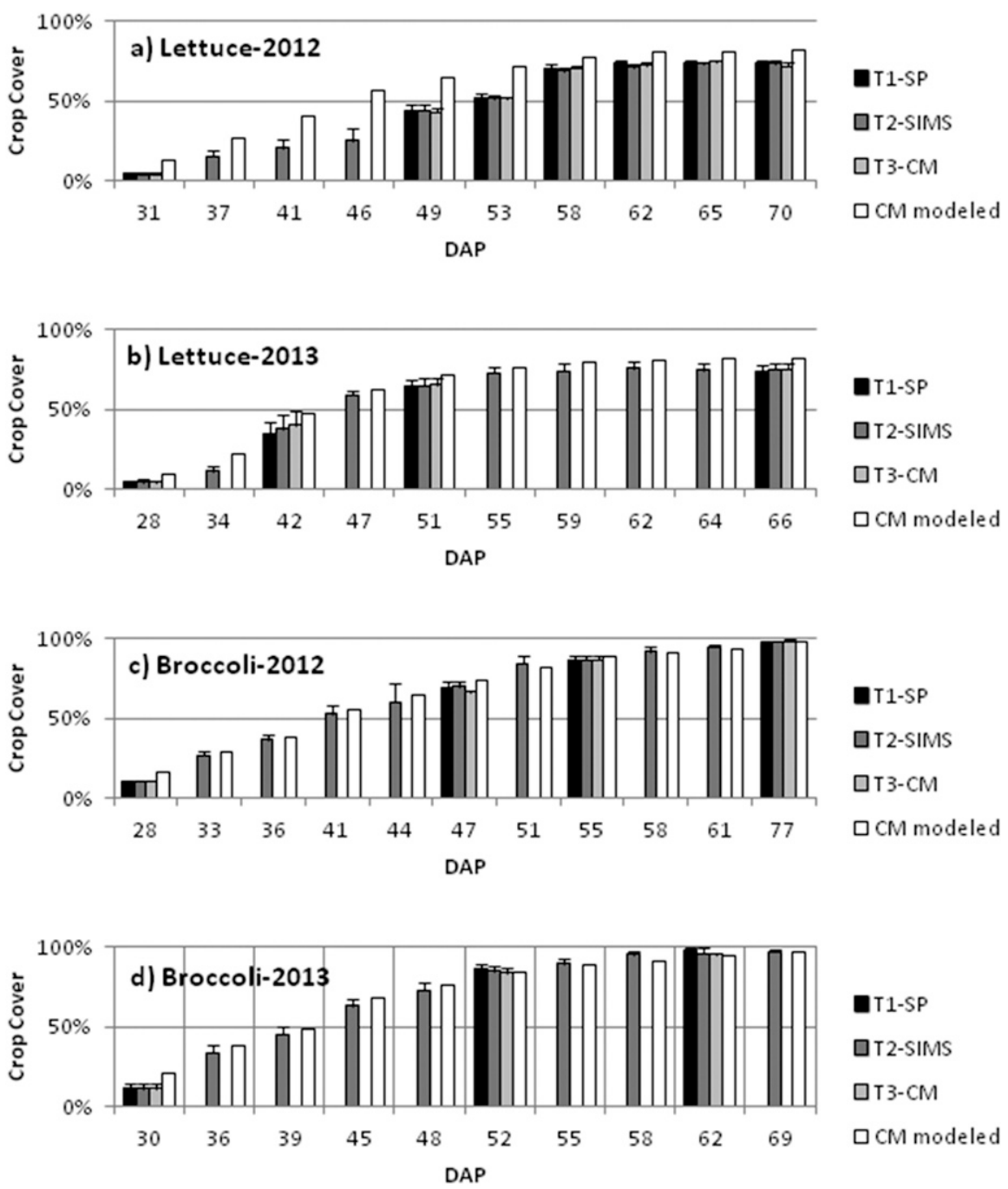

Fig. 1. Measured percent crop cover (mean, SD) vs. days after planting, per trial. Measurements were taken regularly in T2-SIMS to develop irrigation requirements, and periodically in T1-SP and T3-CM plots for comparison purposes. CM modeled predictions shown for reference.

above T1-SP for Broccoli-2012. No difference was seen in T3-CM and T1-SP yield during trials Lettuce-2013 or Broccoli-2013.

Commercial growers have been reluctant to use ET-based scheduling methods for coolseason vegetable crops due to concerns for potential risks to yield and quality, and because of the time required to calculate ET replacement for each field and irrigation event. As a result of having few convenient options for guiding irrigations, vegetable growers generally apply extra water as a margin of insurance against yield loss. In this study, two independently developed models (CM, SIMS) were used in conjunction with CIMIS ETo to guide irrigation scheduling of cool-season vegetable crops at full ET replacement levels. Both models are designed for ease-of-use, require no dedicated on-site sensor installation for routine operation, and thus offer a convenient and cost-effective way to provide customized irrigation schedules on large numbers of fields. The trials achieved commercial yields of lettuce and broccoli under fullreplacement irrigation regimes involving applied water well below that of a standard-practice treatment. Irrigation in excess of ET replacement height. Irr. Sci. 28:17-34.
Cahn, M., R. Smith, T. Hartz, B. Farrara, L. Johnson, and F. Melton. 2014. Irrigation and nitrogen management decision support tool for cool season vegetables and berries. Proc. USCID Water Management Semi-Annual Conference (March), p. 53-64. U.S. Committee on Irrigation and Drainage, Denver CO.

Cahn, M., R. Smith, T. Hartz, and B. Noel. 2013. Irrigation and nitrogen management web-based software for lettuce production. Proc. ASHS Annual Meeting. (abstr.).

Gallardo, M., R. Snyder, K. Schulbach, and L. Jackson. 1996. Crop growth and water use model for lettuce. J. Irr. Drain. Eng. 6:354-359.

Goorahoo, D., F. Cassel-Sharma, T. Thao, F. Melton, and L. Johnson. 2014. An integrated lysimeter and satellite imagery approach for estimating crop evapotranspiration. Proc. AGU Fall Meeting. Amer. Geophys. Union, Washington, DC. (abstr.).

Grattan, S., W. Bowers, A. Dong, R. Snyder, J. Carroll, and W. George. 1998. New crop coefficients estimate water use of vegetable, row crops. Calif. Agr. 52:16-21.

Hart, Q., M. Brugnach, B. Temesgen, C. Rueda, S. Ustin, and K. Frame. 2009. Daily reference evapotranspiration for California using satellite imagery and weather station measurement interpolation. Civ. Eng. Environ. Syst. 26:19-33.

Hatfield, J. and M. Fuchs. 1990. Evapotranspiration models, Chapter 3. In G. Hoffman, T. Howell, and K. Solomon (eds.). Management of Farm Irrigation Systems. Amer. Soc. Agr. Eng., St. Joseph, MI.

Johnson, L., F. Melton, A. Michaelis, L. Pierce, C. Lund, T. Trout, D. Wang, and R. Nemani. 2011. Satellite irrigation management support with the Terrestrial Observation and Prediction System. Proc. 18th Pecora Memorial Remote Sensing Symposium. Amer. Soc. Photogramm. Rem. Sens., Washington, DC.

Johnson, L., R. Nemani, F. Melton, A. Michaelis, P. Votava, D. Wang, and T. Trout. 2010. Information technology supports integration of satellite imagery with irrigation management in California's Central Valley. Proc. 5th National Decennial Irrigation Conference. Amer. Soc. Agr. Bio. Eng., St. Joseph, MI.

Johnson, L. and T. Trout. 2012. Satellite NDVI assisted monitoring of vegetable crop evapotranspiration in California's San Joaquin Valley. Remote Sens. 4:439-455.

generally did not affect crop yields or quality The study incidentally demonstrated the viability of drip irrigation for support of commercial broccoli production in the Salinas Valley.

\section{Literature Cited}

Allen, R., L. Pereira, D. Raes, and M. Smith. 1998 Crop evapotranspiration: Guidelines for computing crop water requirements, FAO irrigation and drainage paper 56. U.N. Food \& Agriculture Organization, Rome.

Allen, R., J. Wright, W. Pruitt, L. Pereira, and M. Jensen. 2007. Water requirements, p. 208 288. In: G. Hoffman, M. Jensen, D. Martin, and R. Elliott (eds.). Design and operation of farm irrigation systems. Amer. Soc. Agric. Bio. Eng., St. Joseph, MI.

Allen, R. and L. Pereira. 2009. Estimating crop coefficients from fraction of ground cover and

Bottoms, T., R. Smith, M. Cahn, and T. Hartz. 2012. Nitrogen requirements and $\mathrm{N}$ status determination of lettuce. HortScience 47:1768-1774.

Bryla, D., T. Trout, and J. Ayars. 2010. Weighing lysimeters for developing crop coefficients and efficient irrigation practices for vegetable crops. HortScience 45:1597-1604.
Lopez-Urrea, R., A. Montoro, P. Lopez-Fuster, and E. Fereres. 2009. Evapotranspiration and responses to irrigation of broccoli. Agr. Water Mgt. 96:1155-1161.

Melton, F., L. Johnson, C. Lund, L. Pierce, A Michaelis, S. Hiatt, A. Guzman, D. Adhikari, A. Purdy, C. Rosevelt, P. Votava, T. Trout, B. Temesgen, K. Frame, E. Sheffner, and R. Nemani. 2012. Satellite Irrigation Management Support with the Terrestrial Observation and Prediction System. IEEE/JSTARS 5:1709-1721.

Monterey County Crop Report. 2013. <http://www. co.monterey.ca.us $/$ Home/ShowDocument?id= $1485>$.

Pruitt, W., E. Fereres, and R. Snyder. 1987. Reference evapotranspiration (ETo) for California. U.C. Cooperative Extension, Bul. 1922.

Temesgen, B., S. Eching, B. Davidoff, and K. Frame. 2005. Comparison of some reference evapotranspiration equations for California. J. Irr. Drain. Eng. 131:73-84.

UC-ANR (Agriculture and Natural Resources). 2010. Broccoli production in California. U.C Regents, Publ. 7211.

UC-ANR (Agriculture and Natural Resources). 2011. Iceberg lettuce production in California, U.C. Regents, Publ. 7215. 